\title{
Parâmetros de Degradabilidade Potencial da Matéria Seca e da Proteína Bruta das Silagens de Seis Genótipos de Sorgo (Sorghum bicolor (L.) Moench), com e sem Tanino no Grão, Avaliados pela Técnica in Situ
}

\author{
Lívio Ribeiro Molina1, Norberto Mario Rodriguez¹, Breno Mourão de Sousa², Lúcio Carlos \\ Gonçalves $^{1}$, Iran Borges ${ }^{1}$
}

\begin{abstract}
RESUMO - Para testar o efeito da presença de tanino no grão sobre os parâmetros de degradabilidade potencial da matéria seca e da proteína bruta de seis genótipos de sorgo para silagem, foi conduzido um experimento utilizando a técnica da degradabilidade in situ. Quatro novilhos canulados no rúmen, alimentados individualmente, duas vezes ao dia ad libitum com feno de Tifton 85 , foram utilizados para a incubação de silagens de sorgo no estádio de grão leitoso, pertencentes a seis genótipos: BR 303, BR 304, BR 601e AG 2006 (sem tanino no grão); BR 700 e BR 701 (com tanino). Foram incubadas 5 g de amostra nos tempos de incubação: 6, 12, 24, 48, 72 e 96 horas. O tempo zero $\left(\mathrm{t}_{0}\right)$ foi utilizado para cálculo da fração solúvel. A presença do tanino reduziu a extensão de degradação da matéria seca e da proteína bruta nas silagens de sorgo BR 700 e BR 701. As degradabilidades potenciais destes nutrientes foram influenciada pelo tanino. Não foi observado efeito depressivo do tanino sobre as taxas de degradação para nenhum nutriente, em nenhuma silagem testada.
\end{abstract}

Palavras-chave: bovino, degradabilidade, rúmen, silagem de sorgo, tanino

\section{Potential Degradability Parameters of the Dry Matter and Crude Protein of Six Sorghum Silage Genotypes (Sorghum bicolor (L.) Moench), with or without Tannin on Grain, Evaluated by in Situ Technique}

\begin{abstract}
The aim of this experiment was to evaluate the effect of tannin on grain over potential degradability parameters of the dry matter and crude protein of six sorghum silage genotypes by in situ technique. It was used four crossbred steers, canulated in rumen, fed ad libitum twice at day with a diet comprised by Cynodon dactylon hay. Six sorghum silage genotypes, harvested at milk stage, were incubated in the rumen: BR 303, BR 304, BR 601, and AG 2006 (without tannin on grain); BR 700, and BR 701 (with tannin on grain). Five grams of samples were incubated at times: $6,12,24,48,72$, and 96 hours. The time zero $\left(\mathrm{t}_{0}\right)$ was used to calculate the soluble fraction. Tannin decrease the extent of degradation of dry matter and crude protein of BR 700 and BR 701 sorghum silages. The potential degradabilities of these nutrients were reduced by tannin presence on grain. There was not effect of tannin on degradation rate of the nutrient compounds in anyone tested sorghum silage.
\end{abstract}

Key Words: cattle, degradability, rumen, sorghum silage, tannin

\section{Introdução}

Os problemas decorrentes da estacionalidade de produção no Brasil central podem ser minimizados pelo armazenamento do alimento na forma de silagem. Diversas gramíneas e leguminosas podem ser utilizadas para produção de silagens. Entretanto, a cultura de sorgo para silagem vem crescendo e representa grande percentual da área cultivada para silagem no Brasil (10 a 12\%). Grande parte desse crescimento advém das altas produções por hectare, bom valor nutritivo e a tolerância a déficits hídricos ocasionais, características da cultura (Pizarro, 1978; Zago, 1991).

Entretanto, Demarchi et al. (1995) mencionaram baixo desempenho produtivo dos animais alimentados com silagem de sorgo em comparação com os alimentados com silagem de milho, justificado pela presença de tanino no grão, que reduziria tanto o consumo quanto a digestibilidade do alimento. Vários autores apontaram ser as proantocianidinas (ou tanino condensado) como a forma predominante de tanino no grão de sorgo (Hagerman \& Butler, 1981; Marinho, 1984; Rodrigues et al., 1998).

Segundo Martins (2000), a qualidade de qualquer

\footnotetext{
1 Departamento de Zootecnia da Escola de Veterinária da Universidade Federal de Minas Gerais/UFMG, Caixa Postal 567, $30123-970$ - Belo Horizonte, MG. Endereço eletrônico: zootec@vet.ufmg.br

2 Autor para Correspondência: Méd. Vet., Mestre em Zootennia, Doutorando do Curso de Ciência Animal da Escola de Veterinária da UFMG, bolsista CNPq. Rua Nunes Vieira, 358/702, Santo Antônio, CEP: 30350-120 - Belo Horizonte, MG. Endereço eletrônico: brenoms@hotmail.com
} 
alimento seria dada pelo valor nutritivo, representado pela composição química do alimento, pela digestibilidade dos seus constituintes, pelo consumo voluntário e pelo desempenho animal. Portanto, a avaliação da digestibilidade de uma forrageira rica em tanino torna-se importante, baseando-se em dois pontos: 1) necessidade de se comparar diferentes forrageiras considerando-se que as mais digestíveis apresentarão melhor retorno econômico/produtivo pelos animais que as consumireme 2) formulação de modelos mecanísticos que expressem progressiva e verdadeiramente o fenômeno dinâmico da digestão, considerando os fatores circunstanciais inerentes ao alimento oferecido (composição, quantidade, freqüência de alimentação etc). Para a avaliação da digestibilidade das forrageiras, seus diversos componentes e principalmente da proteína, idealizaram-se os estudos in situ com bolsas de náilon. Esta técnica tem sido cada vez mais utilizada na avaliação de alimentos utilizados pelos ruminantes, devido a sua facilidade, rapidez de execução e, principalmente, devido a sua alta correlação com resultados obtidos em experimentos in vivo. A técnica ainda oferece parâmetros cinéticos, relacionados a degradabilidade ruminal dos nutrientes, difíceis de serem obtidos em estudos in vitro. Estes parâmetros são de fundamen- tal importância na avaliação nutricional de alimentos para ruminantes (Nocek, 1988).

O objetivo deste trabalho foi avaliar a degradabilidade in situ da matéria seca e da proteína bruta de silagens de seis genótipos de sorgo, sendo dois com tanino no grão (BR 700 e BR 701) e quatro sem tanino (BR 303, BR 304, BR 601 e AG 2006).

\section{Material e Métodos}

Foram utilizados quatro bovinos machos, mestiços Holandês-Zebu, com peso vivo aproximado de $350 \mathrm{~kg}$, canulados no rúmen. Os animais foram alojados em baias individuais nas dependências do Hospital Veterinário da Escola de Veterinária da UFMG, com acesso livre à água e sal mineralizado. Os animais eram alimentados duas vezes ao dia (7 e $17 \mathrm{~h}$ ), unicamente com feno de Tifton 85, ad libitum.

Foram utilizadas silagens de sorgo provenientes de seis genótipos colhidos no estádio de grão leitoso. Foram: BR 303, BR 304, BR 601 e AG 2006 (sem tanino no grão) e BR 700 e BR 701 (com tanino no grão). A composição química (\% da matéria seca MS) das silagens utilizadas para incubação ruminal encontra-se na Tabela 1.

Tabela 1 - Composição química (\% da matéria seca) das silagens de sorgo sem tanino (BR 303, BR 304, BR 601 e AG 2006) e com tanino no grão (BR 700 e BR 701), antes da incubação ruminal

Table 1 - Chemical composition (\% dry matter) of sorghum silages without (BR 303, BR 304, BR 601, and AG 2006) and with tannin (BR 700 and BR 701) on grain, before ruminal incubation

\begin{tabular}{|c|c|c|c|c|c|c|}
\hline \multirow[t]{2}{*}{$\begin{array}{l}\text { Nutriente } \\
\text { Nutrient }\end{array}$} & \multicolumn{6}{|c|}{$\begin{array}{l}\text { Silagens de sorgo } \\
\text { Sorghum silages }\end{array}$} \\
\hline & BR303 & BR 304 & BR 601 & BR 700 & BR 701 & AG 2006 \\
\hline & \multicolumn{6}{|c|}{$\%$ da MS } \\
\hline $\mathrm{MS}(D M)$ & 28,95 & 32,05 & 20,80 & 27,56 & 26,79 & 27,35 \\
\hline $\mathrm{PB}(C P)$ & 7,57 & 8,45 & 5,57 & 6,36 & 6,01 & 6,66 \\
\hline $\mathrm{FDN}(N D F)$ & 41,93 & 38,65 & 54,51 & 51,85 & 52,91 & 50,42 \\
\hline $\operatorname{FDA}(A D F)$ & 25,03 & 22,57 & 33,21 & 33,02 & 32,87 & 30,92 \\
\hline Celulose (Cellulose) & 19,85 & 17,95 & 27,15 & 22,73 & 26,51 & 18,45 \\
\hline Hemicelulose (Hemicellulose) & 16,89 & 16,08 & 21,31 & 18,83 & 20,03 & 19,51 \\
\hline Lignina (Lignin) & 4,21 & 3,33 & 4,49 & 3,65 & 5,03 & 6,73 \\
\hline $\mathrm{pH}(p H)$ & 3,8 & 3,6 & 3,8 & 3,8 & 3,8 & 3,8 \\
\hline $\mathrm{N}-\mathrm{NH}_{3} / \mathrm{NT}\left(\mathrm{N}-\mathrm{NH}_{3} / \mathrm{NT}\right)$ & 8,16 & 8,75 & 11,08 & 10,38 & 11,21 & 10,49 \\
\hline Tanino no grão* & Ausente & Ausente & Ausente & Presente & Presente & Ausente \\
\hline Tannin on grain ${ }^{*}$ & Without & Without & Without & With & With & Without \\
\hline
\end{tabular}

$\mathrm{MS}=$ matéria seca, $\mathrm{PB}=$ proteína bruta, $\mathrm{FDN}=$ fibra detergente neutro, $\mathrm{FDA}=$ fibra detergente ácido, $\mathrm{N}-\mathrm{NH}_{3} / \mathrm{NT}=$ nitrogênio amoniacal em relação ao nitrogênio total. ( $\left.{ }^{*}\right)$ dados obtidos da EMBRAPA Milho e Sorgo/Sete Lagoas-Minas Gerais.

$\left(D M=\right.$ dry matter, $\mathrm{CP}=$ crude protein, $N D F=$ neutral detergent fiber, $A D F=$ acid detergent fiber, $N-N H_{3} / N T=$ ammoniacal nitrogen in relation to total nitrogen). (*) Data obtained from EMBRAPA Milho e Sorgo/Sete Lagoas-Minas Gerais (Brazil).

R. Bras. Zootec., v.32, n.1, p.222-228, 2003 
As amostras experimentais, secas a $65^{\circ} \mathrm{C}$ por 48 horas, foram moídas em peneira de $5 \mathrm{~mm}$ e $5 \mathrm{~g}$ foram acondicionadas em cada bolsa de náilon com poros de $50 \mathrm{~mm}$ e tamanho de $15 \times 8 \mathrm{~cm}$. As bolsas contendo as amostras foram introduzidas dentro do rúmen e ancoradas à parte externa da cânula ruminal através de uma corda de $60 \mathrm{~cm}$ de comprimento. Cada animal continha os tratamentos sob o mesmo tempo de incubação, de modo que todas as bolsas, em um mesmo rúmen, fossem retiradas de uma só vez. Utilizaram-se quatro réplicas de cada genótipo por animal, no mesmo horário. Para determinação do tempo zero $\left(\mathrm{t}_{0}\right)$, três novas réplicas foram feitas para cada genótipo e lavadas manualmente em água corrente por 20 minutos. Através deste procedimento, quantificou-se a fração solúvel de cada alimento.

Os tempos de incubação foram: 6, 12, 24, 48, 72 e 96 horas. Após cada tempo de incubação no rúmen, as bolsas foram imersas em água fria $\left(+4{ }^{\circ} \mathrm{C}\right)$, para cessar a fermentação, e lavadas manualmente em água corrente, até que essa se mostrasse límpida. Após secagem em estufa $65^{\circ} \mathrm{C}$ por 48 horas, as amostras foram pesadas, sendo registrado o peso do resíduo de incubação. Este resíduo foi moído em peneira de $1 \mathrm{~mm}$ para posteriores análises químicas. Estas análises foram feitas tanto para as silagens de sorgo estudadas e quanto para os resíduos de incubação, sendo determinados: teor de matéria seca (MS) em estufa $105^{\circ} \mathrm{C}(\mathrm{AOAC}, 1980)$ e proteína bruta pelo método Kjedhal (AOAC, 1980). As análises foram feitas no Laboratório de Nutrição Animal da Escola de Veterinária da UFMG

As equações de regressão para o desaparecimento da MS e da PB foram estimadas usando o software SAEG 7.0. Para o cálculo da degradabilidade potencial das silagens de sorgo, foi utilizado o modelo proposto por Sampaio (1988), a partir de uma simplificação do modelo exponencial de Ørskov \& McDonald (1979): $\mathbf{P}=\mathbf{A}+\mathbf{B} * \mathbf{e}^{\mathbf{C} t}$, em que $P=$ percentagem real do nutriente degradado após $t$ horas de incubação no rúmen; $A=$ percentagem máxima de degradação do material na bolsa (assíntota); $B=$ fração potencialmente degradável do material que permanece na bolsa após o tempo zero; $C=$ taxa de degradação da fração que permanece na bolsa após o tempo zero.

O delineamento utilizado neste experimento foi o de blocos inteiramente casualizados em um esquema de parcelas sub-subdivididas. As médias para o desaparecimento da MS e da PB dentro das silagens de sorgo entre os tempos de incubação e, dentro dos tempos de incubação, entre as silagens de sorgo, foram comparadas $(\mathrm{p}<0,05)$ utilizando-se o teste de Student-Newman-Keuls (SNK).

\section{Resultados e Discussão}

O desaparecimento médio da matéria seca (MS) das silagens de seis genótipos de sorgo no tempo zero $\left(\mathrm{t}_{0}\right)$ e nos tempos de incubação ruminal (horas) pode ser vistos na Tabela 2 .

As frações solúveis no tempo zero $\left(\mathrm{t}_{0}\right)$ da matéria seca (MS) das silagens de sorgo testadas variaram entre 15,14 a 23,01\%. Rabelo (1997) encontrou para silagens de híbridos de sorgo com altos e baixos teores de tanino no grão, médias de 30,69 e 26,10\%, respectivamente. Serafim (1998), Lara (1999) e Martins et al. (1999) encontraram valores médios de solubilidade no tempo zero de 23,67, 32,80 e 34,7\%, respectivamente. Estes altos valores de solubilidade no tempo zero foram explicados por Sampaio (1988), em que a excessiva moagem do material pode ter produzido um material muito fino que acabou por atravessar os poros da bolsa de incubação, uma vez que as diferentes partes da planta (colmo, folha e, principalmente, grãos/panículas) teriam um comportamento diferente ao serem moídas em peneiras de $5 \mathrm{~mm}$, produzindo uma amostra não homogênea. No entanto, Michalet-Doreau \& Ould-Bah (1992) afirmaram ser razoável assumir que esta partícula não degradada que escapa da bolsa consistiria, principalmente, de material potencialmente degradado, não afetando a degradabilidade final do material incubado.

Ao longo dos tempos de incubação, foi observada estabilização das médias de desaparecimento da MS a partir de $72 \mathrm{~h}$ (exceto para a silagem do sorgo BR $304)$, não diferindo $(\mathrm{p}>0,05)$ para $96 \mathrm{~h}$, mostrando que incubações por $96 \mathrm{~h}$ foram suficientes em atingir os valores máximos de desaparecimento da MS, ou seja, a assíntota. Após 6 horas de incubação ruminal, a silagem do sorgo BR 304 apresentou maior desaparecimento $(p<0,05)$ da MS em relação ao híbrido BR 700. As demais silagens apresentaram resultados intermediários. No tempo de 12 horas, o BR 304 apresentou maior desaparecimento em relação aos híbridos. Às 24 e 48 horas, o BR 304 apresentou maior desaparecimento em relação ao BR 700 e BR 701. As demais silagens de sorgo apresentaram resultados intermediários. No tempo de 72 horas, não houve diferenças $(p>0,05)$ entre as silagens de sorgo

R. Bras. Zootec., v.32, n.1, p.222-228, 2003 
Tabela 2 - Desaparecimento médio da matéria seca (\% da MS) dos genótipos de sorgo para silagem no tempo zero ( $\mathrm{t}_{0}$ ) e nos tempos de incubação ruminal (horas)

Table 2 - Mean disappearance of dry matter (\% of DM) of the sorghum silage genotypes in time zero $\left(t_{0}\right)$ and in incubation times (hours)

\begin{tabular}{|c|c|c|c|c|c|c|}
\hline \multirow[t]{2}{*}{$\begin{array}{l}\text { Tempo de incubação (horas) } \\
\text { Incubation time (hours) }\end{array}$} & \multicolumn{6}{|c|}{$\begin{array}{l}\text { Silagens de sorgo } \\
\text { Sorghum silages }\end{array}$} \\
\hline & BR 303 & BR 304 & BR 601 & BR 700 & BR 701 & AG 2006 \\
\hline$t_{0}$ & 17,31 & 17,47 & 18,27 & 15,14 & 19,49 & 23,01 \\
\hline 6 & $43,57 \mathrm{Eab}$ & $49,01 \mathrm{Ea}$ & $45,67 \mathrm{Dab}$ & $39,85 \mathrm{Db}$ & $40,62 \mathrm{Dab}$ & $41,29 \mathrm{Eab}$ \\
\hline 12 & $51,19 \mathrm{Db}$ & $58,12 \mathrm{Da}$ & $46,15 \mathrm{Db}$ & $43,70 \mathrm{Db}$ & $43,02 \mathrm{Db}$ & $46,36 \mathrm{Db}$ \\
\hline 24 & $58,02 \mathrm{Cab}$ & $63,43 \mathrm{Ca}$ & $58,80 \mathrm{Cab}$ & $50,76 \mathrm{Cb}$ & $53,79 \mathrm{Cb}$ & $56,12 \mathrm{Cab}$ \\
\hline 48 & $70,87 \mathrm{Bab}$ & $73,75 \mathrm{Ba}$ & $67,49 \mathrm{Bab}$ & $64,29 \mathrm{Bb}$ & $63,11 \mathrm{Bb}$ & $67,04 \mathrm{Bab}$ \\
\hline 72 & $75,59 \mathrm{Aa}$ & $74,41 \mathrm{Ba}$ & $75,41 \mathrm{Aa}$ & $70,74 \mathrm{Aa}$ & $68,25 \mathrm{Aa}$ & $73,05 \mathrm{Aa}$ \\
\hline 96 & $79,21 \mathrm{Aa}$ & $82,02 \mathrm{Aa}$ & 78,22 Aab & $70,92 \mathrm{Abc}$ & $69,70 \mathrm{Ac}$ & $75,67 \mathrm{Aabc}$ \\
\hline Tanino no grão* & Ausente & Ausente & Ausente & Presente & Presente & Ausente \\
\hline Tannin on grain ${ }^{*}$ & Without & Without & Without & With & With & Without \\
\hline
\end{tabular}

Médias seguidas pela mesma letra maiúscula não diferem $(p>0,05)$ para a mesma coluna; Médias seguidas pela mesma letra minúscula não diferem $(p>0,05)$ para a mesma linha; Teste SNK; $C V: 5,51 \%$.

Mean values followed by the same capital letters in the column, did not differ ( $p>0.05)$; Mean values followed by the same minute letters in the row, did not differ ( $p>0.05$ ); Student-Newman-Keuls test; CV: $5.51 \%$.

testadas para o desaparecimento médio da MS. Às 96 horas, as silagens dos genótipos BR 303 e BR 304 apresentaram maior $(\mathrm{p}<0,05)$ desaparecimento da MS em relação as do BR 700 e BR 701. As silagens do BR 601 e AG 2006 apresentaram resultados intermediários.

Às 96 horas, as silagens de sorgo com tanino no grão (BR 700 e BR 701) apresentaram menores médias para o desaparecimento da MS em relação aos sorgos BR 303 e BR 304. Portanto, a presença de tanino nos alimentos parece ter diminuído a degradabilidade da MS. Em outros estudos, a degradação in vitro da MS de alguns alimentos, entre eles o sorgo como forrageira, foi correlacionada negativamente com a concentração de tanino (Cummins, 1971; Kumar \& Singh, 1984; Zago, 1991). Em sua revisão, Sousa (2001) justifica o efeito deletério do tanino sobre a digestibilidade da MS como sendo originado de: 1) inibição das enzimas digestivas microbianas, 2) inibição do crescimento microbiano; 3) indisponibilização do substrato para a microbiota ruminal, através da formação de complexos substratotanino insolúveis.

Os valores médios de desaparecimento da MS se adequaram ao modelo exponencial proposto por Ørskov \& McDonald (1979), adaptado por Sampaio (1988). As equações de degradabilidade potencial da MS, para cada silagem, foram: $\begin{array}{ll}\text { BR 303: } \mathrm{P}=82,25+44,93 * \mathrm{e}^{-0,0275 t ;} & \mathrm{R}^{2}=0,913 \\ \text { BR 304: } \mathrm{P}=81,71+37,47 * \mathrm{e}^{-0,0308 t ;} & \mathrm{R}^{2}=0,846 \\ \text { BR 601: } \mathrm{P}=84,20+45,69 * \mathrm{e}^{-0,0218 t ;} & \mathrm{R}^{2}=0,912 \\ \text { BR 700: } \mathrm{P}=76,28+43,44 * \mathrm{e}^{-0,0251 t ;} & \mathrm{R}^{2}=0,857 \\ \text { BR 701: } \mathrm{P}=72,41+39,35 * \mathrm{e}^{-0,0298 t ;} & \mathrm{R}^{2}=0,867 \\ \text { AG 2006: } \mathrm{P}=78,93+44,78 * \mathrm{e}^{-0,0277 t} ; & \mathrm{R}^{2}=0,903\end{array}$

A degradabilidade potencial (parâmetro A da equação de Sampaio, 1988) das silagens dos sorgos BR 700 $(76,41 \%)$ e BR $701(72,41 \%)$ foram menores que a das demais, que variaram de 78,93 a $84,20 \%$. O menor valor para aquelas duas amostras testadas pode ter sido conseqüência da presença de tanino no grão. Não foi observado efeito depressivo do tanino sobre as taxas de degradação (parâmetro C) das silagens de sorgo testadas, que variaram de 2,18 a $3,08 \% / \mathrm{h}$.

O desaparecimento médio da proteína bruta (PB) das silagens de seis genótipos de sorgo no tempo zero (to) e nos tempos de incubação ruminal (horas) podem ser vistos na Tabela 3 .

As silagens dos seis genótipos de sorgo apresentaram resultados de solubilidade da $\mathrm{PB}\left(\mathrm{t}_{0}\right)$ variando entre 19,55 e $23,01 \%$, que representa a porção de nitrogênio solúvel ou suficientemente moído em partículas pequenas para sair pelos poros da bolsa de incubação. Após 6 horas de incubação ruminal, as silagens de sorgo BR 303, BR 304 e AG 2006 apresentaram maior desaparecimento da $\mathrm{PB}$ em re- 
Tabela 3 - Desaparecimento médio da proteína bruta (\% da PB) dos genótipos de sorgo para silagem no tempo zero $\left(\mathrm{t}_{0}\right)$ e nos tempos de incubação ruminal (horas)

Table 3 - Mean disappearance of crude protein (\% of CP) of the sorghum silage genotypes in time zero ( $t_{0}$ ) and in incubation times (hours)

\begin{tabular}{|c|c|c|c|c|c|c|}
\hline \multirow[t]{2}{*}{$\begin{array}{l}\text { Tempo de incubação (horas) } \\
\text { Incubation time (hours) }\end{array}$} & \multicolumn{6}{|c|}{$\begin{array}{l}\text { Silagens de sorgo } \\
\text { Sorghum silages }\end{array}$} \\
\hline & BR303 & BR 304 & BR 601 & BR 700 & BR 701 & AG 2006 \\
\hline$\overline{\mathrm{T}_{0}}$ & 21,54 & 22,28 & 22,74 & 19,55 & 22,83 & 23,01 \\
\hline $6^{0}$ & $63,12 \mathrm{Ba}$ & $62,82 \mathrm{Ca}$ & $48,53 \mathrm{Cb}$ & $48,07 \mathrm{Cb}$ & $48,51 \mathrm{Cb}$ & $63,27 \mathrm{Ca}$ \\
\hline 12 & $62,21 \mathrm{Bab}$ & $71,21 \mathrm{BCa}$ & $64,92 \mathrm{Bab}$ & $56,10 \mathrm{Bb}$ & $45,92 \mathrm{Cc}$ & $65,14 \mathrm{Cab}$ \\
\hline 24 & $67,71 \mathrm{Ba}$ & $71,37 \mathrm{BCa}$ & $68,96 \mathrm{Ba}$ & $59,85 \mathrm{Ba}$ & $64,61 \mathrm{Ba}$ & $70,04 \mathrm{Ba}$ \\
\hline 48 & $76,34 \mathrm{Aa}$ & $76,18 \mathrm{ABa}$ & $73,26 \mathrm{ABa}$ & $68,39 \mathrm{Aa}$ & $71,33 \mathrm{ABa}$ & $76,36 \mathrm{ABa}$ \\
\hline 72 & $79,26 \mathrm{Aa}$ & $78,41 \mathrm{ABa}$ & $78,42 \mathrm{Aa}$ & $73,89 \mathrm{Aa}$ & $74,82 \mathrm{Aa}$ & $76,35 \mathrm{ABa}$ \\
\hline 96 & $80,61 \mathrm{Aa}$ & $82,02 \mathrm{Aa}$ & $80,36 \mathrm{Aa}$ & $74,16 \mathrm{Aa}$ & $75,21 \mathrm{Aa}$ & $81,75 \mathrm{Aa}$ \\
\hline Tanino no grão* & Ausente & Ausente & Ausente & Presente & Presente & Ausente \\
\hline Tannin on grain ${ }^{*}$ & Without & Without & Without & With & With & Without \\
\hline
\end{tabular}

Médias seguidas pela mesma letra maiúscula não diferem $(p>0,05)$ para a mesma coluna; Médias seguidas pela mesma letra minúscula não diferem $(p>0,05)$ para a mesma linha; Teste SNK; Coeficiente de variação: $8,57 \%$.

Mean values followed by the same capital letters in the column, didn't differed ( $p>0.05)$; Mean values followed by the same minute letters in the row, did not differ ( $p>0.05)$; Student-Newman-Keuls test; CV: $8.57 \%$.

lação às silagens de BR 700, BR 701 e BR 601. No tempo de 12 horas, o BR 304 apresentou maior desaparecimento em relação ao BR 700 e BR 701. Valores intermediários foram apresentados pelas silagens dos genótipos AG 2006, BR 601 e BR 303, que foram semelhantes ao BR 304 e BR 700 e superiores ao BR 701. Às 24, 48, 72 e 96 horas, não houve diferenças entre as silagens de sorgo testadas quanto ao desaparecimento da PB.

Apesar de não haver diferença $(p>0,05)$ para a média de desaparecimento da $\mathrm{PB}$ às 96 horas, as silagens dos sorgos com tanino no grão, BR 700 e BR 701 , numericamente, apresentaram os menores resultados entre as silagens testadas $(74,16$ e $75,21 \%$, respectivamente). Uma possível explicação para a falta de significância entre os materiais incubados às 96 horas foi o elevado valor do coeficiente de variação observado para o desaparecimento da $\mathrm{PB}(8,57 \%)$ que, conforme relatado por Rabelo (1997), seria uma conseqüência da falta de homogeneidade das amostras incubadas no rúmen. Sousa (2001) encontrou coeficiente de variação para a média de desaparecimento da PB inferior ao deste experimento $(2,66 \%)$.

A habilidade dos taninos de interagirem com as proteínas formando complexos tanino-proteína resistentes ao ataque microbiano seria o mais importante efeito nutricional e toxicológico destes compostos (Rittner \& Reed, 1992; Reed, 1995). No entanto, parece haver maior afinidade dos taninos pelas proteínas do que por outras moléculas (como a celulose), o que foi atribuído às fortes pontes de hidrogênio que se formariam entre o oxigênio do grupo carbonila das proteínas e os grupos hidroxifenólicos dos taninos (McLeod, 1974).

Kumar \& Singh (1984) mencionaram quatro tipos de ligações para a formação do complexo taninoproteína: 1) pontes de hidrogênio entre fenóis e os grupos hidroxila das proteínas, 2) pontes ou interações iônicas entre o ânion fenolato e o sítio catiônico da molécula protéica, 3) interações hidrofóbicas entre a estrutura do anel aromático dos compostos fenólicos e as regiões hidrofóbicas das proteínas e 4) ligações covalentes formadas pela oxidação dos polifenóis a quinonas e subseqüente condensação com os grupos nucleofílicos $\left(-\mathrm{NH}_{2},-\mathrm{SH},-\mathrm{OH}\right)$ das proteínas.

Os valores médios de desaparecimento da PB se adequaram ao modelo exponencial proposto por Ørskov \& McDonald (1979), adaptado por Sampaio (1988). As equações de degradabilidade potencial da $\mathrm{PB}$, para cada silagem, foram:

$\begin{array}{ll}\text { BR 303: } \mathrm{P}=88,30+30 * \mathrm{e}^{-0,0163 t ;} & \mathrm{R}^{2}=0,840 \\ \text { BR 304: } \mathrm{P}=90,00+30 * \mathrm{e}^{-0,0166 t ;} & \mathrm{R}^{2}=0,673 \\ \text { BR 601: } \mathrm{P}=77,69+44,0 \mathrm{e}^{*} \mathrm{e}^{-0,0800 t ;} ; & \mathrm{R}^{2}=0,565 \\ \text { BR 700: } \mathrm{P}=76,11+32,48 * \mathrm{e}^{-0,0311 t ;} & \mathrm{R}^{2}=0,820 \\ \text { BR 701: } \mathrm{P}=76,33+40,23 * \mathrm{e}^{-0,0401 t ;} & \mathrm{R}^{2}=0,726 \\ \text { AG 2006: } \mathrm{P}=90,00+30 * \mathrm{e}^{-0,0132 t ;} & \mathrm{R}^{2}=0,791\end{array}$

Os potenciais de degradação da PB encontrados nesse experimento foram semelhantes aos obtidos por Serafim (1998), que encontrou valores variando entre 78 a $95 \%$. No entanto, foram superiores aos 
37,30\% obtidos por Martins et al. (1999), para silagens de sorgo.

Numericamente, os resultados observados para a degradabilidade potencial do BR $700(76,11 \%)$ e do BR $701(76,33 \%)$ foram os menores entre as silagens de sorgo testadas. Isto leva a pensar sobre uma possível influência do tanino sobre o potencial de degradação da $\mathrm{PB}$, conforme descrito anteriormente.

Para a silagem de alguns genótipos de sorgo, a taxa de degradação da fração lentamente degradável (1,63\%/h no BR 303, 1,66\%/h no BR 304 e 1,32\%/h o AG 2006) mostrou-se aquém do esperado, já que, para Sampaio (1988), o parâmetro $C$ da equação $\mathrm{P}=\mathrm{A}+\mathrm{B}^{*} \mathrm{e}^{-\mathrm{Ct}}$, geralmente será de 2 a $6 \%$ para a maioria dos alimentos vegetais de boa qualidade. Por outro lado, a silagem do BR 601 deste experimento superou em 33\% o maior valor sugerido pelo autor $(8,00 \% / \mathrm{h})$.

Analisando os resultados da equação para a taxa de degradação $(C)$ da $\mathrm{PB}$, parece que a presença de tanino no grão das silagens de sorgo BR 700 e BR 701 não exerceu efeito deletério sobre esse parâmetro.

\section{Conclusões}

A incubação de amostras de silagem de sorgo em bolsas de náilon suspensas no rúmen por até $96 \mathrm{~h}$ mostrou-se suficiente em atingir os valores máximos de desaparecimento da MS e da PB, ou seja, a assíntota.

A presença de tanino em genótipos de sorgo ensilado no estádio de grão leitoso, parece ter reduzido a extensão de degradação (média de desaparecimento às 96 horas) e a degradabilidade potencial para a matéria seca nas silagens de sorgo BR 700 e BR 701.

$\mathrm{O}$ tanino pode ter influenciado na extensão e no potencial de degradação da proteína bruta nas silagens de sorgo BR 700 e BR 701. No entanto, a presença de tanino no grão não influenciou as taxas de degradação das amostras de silagens de sorgo incubadas no rúmen para matéria seca e proteína bruta.

\section{Literatura Citada}

ASSOCIATION OFFICIAL ANALYTICAL CHEMISTS (AOAC). Official methods of analysis. 13.ed. Washington. D.C.: AOAC. 1980. 1015p.

CUMMINS, D.G. Relationships between tannin content and forage digestibility in sorghum. Agronomy Journal. v.63, n.3, p.500-502, 1971.

DEMARCHI, J.J.A.A.; BOIN, C.; BRAUN, G. A cultura do sorgo (Sorghum bicolor L. Moench) para a produção de silagens de alta qualidade. Zootecnia, v.33, n.3, p.111-136, 1995.

R. Bras. Zootec., v.32, n.1, p.222-228, 2003
HAGERMAN, A.E.; BUTLER, L.G. The specificity of proanthocyanidin-protein interactions. The Journal of Biological Chemistry, v.256, n.9, p.4494-4497, 1981.

KUMAR, R.; SINGH, M. Tannins: their adverse role in ruminant nutrition. Journal of Agricultural and Food Chemistry, v.32, n.3, p.447-453, 1984.

LARA, A.C. Degradabilidade in situ dos componentes nutricionais das silagens do sorgo BR 601 colhidos em três estádios de maturação. Belo Horizonte: Universidade Federal de Minas Gerais, 1999. 67p. Dissertação (Mestrado em Zootecnia) - Universidade Federal de Minas Gerais, 1999.

MARINHO, A.A.M. Influência dos taninos no comportamento dos microrganismos e suas implicações nas transformações microbianas no trato gastrintestinal dos ruminantes. Revista Portuguesa de Ciências Veterinárias, v.79, n.469, p.5-21, 1984.

MARTINS, A.S., ZEOULA, L.M., PRADO, I.N. et al. Degradabilidade ruminal in situ da matéria seca e proteína bruta das silagens de milho e sorgo e de alguns alimentos concentrados. Revista Brasileira de Zootecnia, v.28, n.5, p.1109-1117, 1999.

MARTINS, R.G.R. Consumo e digestibilidade aparente das silagens de quatro genótipos de sorgo [Sorghum bicolor (L.) Moench] em ovinos. Belo Horizonte: Universidade Federal de Minas Gerais, 2000. 45p. Dissertação (Mestrado em Zootecnia) - Universidade Federal de Minas Gerais, 2000.

McLEOD, M.N. Plant tannins - their role in forage quality. Nutrition Abstracts and Reviews, v.44, n.11, p.803-815, 1974 .

MICHALET-DOREAU, B.; OULD-BAH, M.Y. In vitro and in sacco methods for the estimation of dietary nitrogen degradability in the rumen: a review. Animal Feed Science and Technology, v.40, p.57-86, 1992.

NOCEK, J.E. In situ and other methods to estimate ruminal protein and energy digestibility: a review. Journal of Dairy Science, v.71, n.8, p.2051-2069, 1988.

ØRSKOV, E.R.; McDONALD, I. The estimation of protein degradability in the rumen from incubation measurements weighted according to rate of passage. Journal of Agriculture Science, v.92, p.499-503, 1979.

PIZARRO, E.A. Alguns fatores que afetam o valor nutritivo da silagem de sorgo. Informe Agropecuário, v.4, n.47, p.12-19, 1978.

RABELO, E. Degradabilidade in situ de silagens de híbridos de sorgo [Sorghum bicolor (L.) Moench] de porte médio com diferentes teores de taninos e suculência no colmo. Belo Horizonte: Universidade Federal de Minas Gerais, 1997. 98p. Dissertação (Mestrado em Zootecnia) - Universidade Federal de Minas Gerais, 1997.

REED, J.D. Nutritional toxicology of tannins and related polyphenols in forage legumes. Journal of Animal Science, v.73, n.5, p.1516-1528, 1995.

RITTNER, U.; REED, J.D. Phenolics and in vitro degradability of protein and fibre in west African browse. Journal of the Science and Food Agriculture, v.58, n.1, p.21-28, 1992.

RODRIGUES, W.A.; MAGALHÃES, P.C.; SANTOS, F.G. et al. Métodos para determinar taninos em sorgo, avaliando-se o desempenho de aves e a digestibilidade in vitro da matéria seca. Ciência e Agrotecnologia, v.22, n.4, p.540-550, 1998.

SAMPAIO, I.B.M. Experimental designs and modeling techniques in the study of roughage degradation in rumen and growth of ruminants. Reading: University of Reading, 1988. 214p. Tese (Doutorado em Fisiologia) University of Reading, 1988. 
SERAFIM, M.V. Degradabilidade in situ dos componentes nutricionais das silagens de três cultivares de sorgo (BR 303, BR 601 e BR 700). Belo Horizonte: Universidade Federal de Minas Gerais, 1998. 87p. Dissertação (Mestrado em Zootecnia, Nutrição Animal) - Universidade Federal de Minas Gerais, 1998.

SOUSA, B.M. Degradabilidade in situ dos componentes nutricionais das silagens de três genótipos de sorgo (CMSXS 180, CMSXS 227 e BR 700). Belo Horizonte: Universidade Federal de Minas Gerais, 2001. 73p. Dissertação (Mestrado em Zootecnia) - Universidade Federal de Minas Gerais, 2001.
ZAGO, C.P. Cultura de sorgo para produção de silagem de alto valor nutritivo. In: SIMPÓSIO SOBRE NUTRIÇÃO DE BOVINOS, 4., 1991, Piracicaba. Anais... Piracicaba: Fundação de Estudos Agrários "Luiz de Queiroz", 1991. p.169218.

Recebido em:22/05/02

Aceito em: 11/09/02 